\title{
Respons Poliembrioni Dari Biji Duku (Lansium domesticum Corr.) yang Dibelah Tiga Secara In Vitro
}

\section{Polyembryonic Response from Seeds of Lansium domesticum Corr. Longitudinally Three-Divided In Vitro}

\author{
Syafia Diang Rana ${ }^{1 *}$, Reza Puspita Dewi ${ }^{1}$, Agung Purnomo Adjie ${ }^{1}$, Mayta Novaliza Isda ${ }^{1}$ \\ ${ }^{1}$ Jurusan Biologi FMIPA Universitas Riau. Kampus Binawidya Pekanbaru 28293, Riau, Indonesia \\ E-mail : syafiadiangrana08@gmail.com *Penulis Korespondensi
}

\begin{abstract}
Duku (Lansium domesticum Corr.) was one of the tropical fruit with economic value that has high demand in the market due to its sweet taste and nutritional value. This fruit has polyembryonic seeds that will produce a higher number of new plants with similar characteristics to their parental plants. Propagation by in vitro technique will produce large plant quantity in a shorter time compared to the conventional method. The study aimed to determine the poliembryoni response of Lansium domesticum, which longitudinally divided into three parts, with the addition of BAP (Benzyl Amino Purine) using test-tube. This study used a completely randomized design (CRD) using the concentrations of $B A P=0,1,3,5$, and $7 \mathrm{mg} / \mathrm{L} \mathrm{BAP}$. The results showed that the fastest shoot time was 2.20 weeks after planting at a concentration of $1 \mathrm{mg} / \mathrm{L} \mathrm{BAP}$. The highest number of shoots (2.00) was in $3 \mathrm{mg} / \mathrm{L}$ BAP treatment. The treatment of the concentrations of BAP was not able to increase the number of plant shoots.
\end{abstract}

Keywords: BAP (Benzyl amino purine), in vitro, polyembryonic, Lansium domesticum Corr.

\begin{abstract}
Abstrak
Duku (Lansium domesticum Corr.) adalah salah satu buah tropis bernilai ekonomis yang diminati oleh masyarakat dengan rasa manis dan bernilai gizi tinggi. Biji duku memiliki sifat poliembrioni yang akan menghasilkan tanaman lebih banyak dan seragam sesuai dengan induknya. Perbanyakan dengan teknik in vitro akan menghasilkan tanaman dalam jumlah yang banyak dalam waktu yang relatif singkat dibandingkan secara konvensional. Tujuan penelitian yaitu untuk mengetahui respon poliembrioni biji duku yang dibelah tiga secara membujur dengan penambahan BAP (Benzyl Amino Purine) secara in vitro. Penelitian ini menggunakan Rancangan Acak Lengkap dengan konsentrasi $B A P=0,1,3,5$ dan 7 mg/L BAP. Hasil penelitian menunjukkan bahwa waktu muncul tunas tercepat yaitu 2,20 MST pada konsentrasi $1 \mathrm{mg} / \mathrm{L}$ BAP. Jumlah tunas tertinggi pada perlakuan $3 \mathrm{mg} / \mathrm{L}$ BAP yaitu 2,00 tunas, namun perlakuan pemberian konsentrasi BAP belum mampu meningkatkan jumlah tunas.
\end{abstract}

Kata kunci: BAP (Benzyl amino purine), in vitro, poliembrionik, Lansium domesticum Corr.

Diterima: 30 April 2019, disetujui: 20 Mei 2019

\section{Pendahuluan}

Duku (Lansium domesticum Corr.) adalah salah satu buah tropis yang diminati masyarakat. Di Indonesia tanaman dari genus Lansium satu ini sebenarnya masih berkerabat dengan buah langsat dan kokosan. Tanaman duku di Indonesia penyebarannya di Kalimantan, Sulawesi, Jawa dan Sumatera. Daerah tertentu menjadikan duku sebagai buah yang penting (Susilawati et al. 2016).

Menurut Supriatna dan Suparwoto (2010) buah duku bermanfaat untuk memperlancar sistem pencernaan, pencegahan kanker kolon dan membersihkan tubuh dari radikal bebas. Tanaman duku berpotensi untuk dikembangkan. Perbanyakan duku banyak dilakukan menggunakan biji dari pada teknik sambung pucuk. Sebab, teknik sambung pucuk memerlukan batang bawah dengan perakaran yang baik. Salah satu metode yang dapat digunakan untuk mengatasi hal tersebut adalah teknik kultur in vitro.

Media dalam perbanyakan secara in vitro yang paling banyak digunakan adalah media Murashige Skoog (MS) karena memiliki 
kandungan unsur hara makro dan mikro yang cukup tinggi (Rahmawati et al. 2014). Zat Pengatur Tumbuh (ZPT) juga perlu ditambahkan dalam media kultur in vitro untuk menopang pertumbuhan eksplan menjadi individu baru yang lengkap. ZPT yang biasa digunakan salah satunya adalah Benzyl Amino Purin (BAP) dari golongan sitokinin. BAP mampu merangsang pembelahan sel secara baik, sehingga eksplan akan membentuk nodul (Hariono et al. 2018).

Duku merupakan salah satu tanaman yang memiliki biji yang bersifat poliembrioni. Prihatini et al. (2010) menyatakan bahwa dari penanaman biji duku utuh pada media MS, 1/2 MS dan WPM dengan penambahan air kelapa 0, $15 \%$ dan $20 \%$ menghasilkan $20-30 \%$ biji duku bersifat poliembrioni. Adanya sifat poliembrioni pada duku memungkinkan untuk menghasilkan bibit yang banyak, serta dengan adanya pembelahan pada eksplan biji diharapkan akan menginduksi pembentukan tunas lebih banyak. Berdasarkan uraian tersebut maka dilakukan penelitian ini untuk mengetahui respons poliembrioni pada biji duku (Lansium domesticum Corr.) dengan penambahan BAP pada eksplan biji yang dibelah tiga membujur secara in vitro.

\section{Metode Penelitian}

\section{Bahan dan Alat}

Bahan-bahan yang digunakan adalah biji duku (Lancium domesticum Corr.) dari pasar buah Pekanbaru, media Murashige Skoog (MS), Benzyl Amino Purine (BAP), akuades, gula, agar, $\mathrm{KOH} 1 \mathrm{~N}, \mathrm{HCl} 1 \mathrm{~N}$, alkohol $70 \%$, detergen, pemutih, bakterisida, fungisida, tween 20, kertas saring, tisssue gulung, aluminium foil, kertas label, plastik kaca dan karet gelang.

Alat-alat yang digunakan dalam penelitian ini adalah Air Flow Cabinet (LAFC) (Lab Tech), autoklaf, oven, rak kultur, timbangan analitik, hotplate, $\mathrm{pH}$ meter, erlenmeyer, botol kultur, gelas ukur, pipet tetes, gelas kimia, cawan petri, pinset, spatula, skalpel, lampu bunsen, gunting, batang pengaduk, botol sprayer dan panci.

\section{Rancangan Penelitian}

Penelitian ini menggunakan Rancangan Acak Lengkap (RAL) yang terdiri atas lima perlakuan yang merupakan konsentrasi BAP (Kontrol, 1, 3, 5 dan $7 \mathrm{mg} / \mathrm{L}$ BAP) dengan lima kali ulangan, sehingga diperoleh 25 unit percobaan.

\section{Prosedur Kerja}

Eksplan yang digunakan dalam penelitian ini adalah biji duku (Lansium domesticum Corr.) dari buah yang sudah matang didapatkan dari Pasar Buah Pekanbaru, Riau. Alat-alat yang akan digunakan seperti botol kultur, cawan petri, pinset, scapel dan lain-lain disterilkan menggunakan autoklaf pada suhu $121^{\circ} \mathrm{C}$ dengan tekanan 15 Psi selama 15 menit (Syah 2016).

Pembuatan media $1 \mathrm{~L}$ dilakukan dengan menimbang komponen media seperti gula pasir $30 \mathrm{~g}$, agar $7 \mathrm{~g}$ dan media MS 4,33 g, kemudian dilarutkan dalam $1000 \mathrm{ml}$ akuades ditambah konsentrasi BAP sesuai dengan perlakuan $(0,1,3,5$ dan $7 \mathrm{mg} / \mathrm{L})$. Larutan dikondisikan pada $\mathrm{pH}$ 5,8 kemudian dimasak di atas hotplate hingga mendidih. Setelah mendidih larutan dimasukkan ke dalam botol kultur $\pm 30 \mathrm{ml}$. Botol ditutup alumunium foil dan ditutup kembali menggunakan plastik lalu diikat dengan karet. Media disterilisasi dengan menggunakan autoklaf pada suhu $121^{\circ} \mathrm{C}$ dengan tekanan 15 psi. Setelah sterilisasi media diuji kontaminasi selama \pm 1 minggu (Hariono et al. 2018). Biji buah duku dibersihkan dan dicuci hingga bersih dari arilnya. Kemudian dilakukan sterilisasi eksplan di luar dan di dalam LAFC. Sebelum melakukan penanaman LAFC disterilisasi menggunakan alkohol $70 \%$ dan UV LAFC dibiarkan menyala selama 60 menit. Peralatan yang digunakan dalam proses penanaman disemprot terlebih dahulu menggunakan alkohol $70 \%$ kemudian dimasukkan dalam LAFC. Eksplan biji duku yang telah disterilisasi dibelah menggunakan skalpel dan pinset menjadi 3 bagian secara membujur. Kemudian eksplan biji ditanam dalam media perlakuan. Parameter yang diamati meliputi waktu muncul tunas (MST), jumlah tunas, tinggi tunas, jumlah daun, waktu muncul akar (MST) dan jumlah akar pada 8 minggu setelah tanam.

\section{Analisis Data}

Data hasil pengamatan dianalisis secara statistik menggunakan ANOVA pada program 
SPSS versi 17 , apabila terdapat pengaruh nyata dilanjutkan dengan uji DMRT pada taraf 5\% (Hariono et al. 2018).

\section{Hasil dan Pembahasan}

Respons poliembrioni biji duku (Lansium domesticum Corr.) yang dibelah menjadi tiga bagian secara membujur dengan penambahan BAP pada media MS belum menunjukkan hasil yang signifikan pada parameter yang diamati. Ini disebabkan nilai yang tidak terlalu jauh berbeda antar perlakuan. Berdasarkan hasil analisis ANOVA menunjukkan bahwa pemberian konsentrasi $\operatorname{BAP}(0,1,3,5$ dan $7 \mathrm{mg} / \mathrm{L})$ berpengaruh nyata terhadap waktu muncul tunas, namun tidak berpengaruh nyata terhadap jumlah tunas, waktu muncul akar dan jumlah akar yang diamati 8 minggu setelah tanam (MST).

Tabel 1. Pengaruh pemberian BAP terhadap waktu muncul tunas (MST), jumlah tunas (tunas), tinggi tunas (cm) dan jumlah daun (daun)

\begin{tabular}{ccccc}
\hline \hline \multirow{2}{*}{ Perlakuan } & \multicolumn{4}{c}{ Parameter } \\
\cline { 2 - 5 } & $\begin{array}{c}\text { Waktu Muncul Tunas } \\
(\text { MST) }\end{array}$ & $\begin{array}{c}\text { Jumlah Tunas } \\
\text { (Tunas) }\end{array}$ & $\begin{array}{c}\text { Tinggi Tunas } \\
(\mathbf{c m})\end{array}$ & $\begin{array}{c}\text { Jumlah Daun } \\
\text { (Helai daun) }\end{array}$ \\
\hline \hline Kontrol & $4,00^{\mathrm{ab}}$ & 1,00 & $1,12^{\mathrm{a}}$ & 0,8 \\
1 BAP & $2,20^{\mathrm{a}}$ & 1,60 & $2,28^{\mathrm{b}}$ & 2,6 \\
3 BAP & $4,40^{\mathrm{b}}$ & 2,00 & $0,90^{\mathrm{a}}$ & 1,4 \\
5 BAP & $4,80^{\mathrm{b}}$ & 1,60 & $0,84^{\mathrm{a}}$ & 0,4 \\
7 BAP & $7,80^{\mathrm{c}}$ & 1,60 & $0,38^{\mathrm{a}}$ & 0,6 \\
\hline \hline
\end{tabular}

Keterangan : Angka yang diikuti oleh huruf yang berbeda pada kolom yang sama menunjukkan berbeda nyata $(\mathrm{p}<0,05)$ pada uji DMRT taraf $5 \%$

\section{Waktu Muncul Tunas}

Berdasarkan data yang telah disajikan pada Tabel 1. dapat dilihat bahwa waktu muncul tunas yang dihasilkan berkisar antara 2,20 - 7,80 minggu setelah tanam. Berdasarkan hasil analisis ANOVA dan uji lanjut DMRT menunjukkan bahwa waktu muncul tunas pada pemberian $7 \mathrm{mg} / \mathrm{L}$ BAP berbeda nyata terhadap kontrol dan $1 \mathrm{mg} / \mathrm{L}$ BAP, namun tidak berbeda nyata terhadap pemberian 3 dan $5 \mathrm{mg} / \mathrm{L}$ BAP. Waktu muncul tunas tercepat terjadi pada perlakuan $1 \mathrm{mg} / \mathrm{L}$ BAP yaitu 2,20 MST, sedangkan waktu muncul tunas paling lama terjadi pada perlakuan $7 \mathrm{mg} / \mathrm{L}$ BAP yaitu 7,80 MST. Hal ini diduga bahwa pada eksplan biji duku yang dibelah secara membujur memerlukan tambahan sitokinin dalam konsentrasi yang lebih rendah dari $1 \mathrm{mg} / \mathrm{L}$ BAP.

Perbedaan waktu muncul tunas tersebut diduga dipengaruhi oleh konsentrasi BAP yang diberikan. Hasil yang sama didapatkan oleh Triatminingsih et al. (2003) menggunakan eksplan biji duku utuh dengan pemberian $1 \mathrm{ppm}$ BAP menghasilkan waktu muncul tunas tercepat, yaitu 2 minggu setelah penanaman. Pemberian konsentrasi BAP yang terlalu tinggi $=3,5$ dan $7 \mathrm{mg} / \mathrm{L}$ tidak lagi memacu pembentukan tunas, tetapi menghambat pembentukan tunas. Sebab Zat Pengatur Tumbuh (ZPT) memicu pertumbuhan pada konsentrasi yang rendah, apabila diberikan pada konsentrasi tinggi akan menimbulkan kebalikan dari fungsinya, karena hormon bekerja pada konsentrasi yang sedikit dan paling optimal. Menurut Fathurrahman et al. (2012) pemberian sitokinin sampai konsentrasi tertentu berpengaruh dalam waktu muncul tunas, hal tersebut sesuai dengan fungsi sitokinin sebagai ZPT pemicu pembentukan tunas. Selain itu, pembentukan tunas juga dapat dipengaruhi oleh tingkat perkembangan embrio dalam biji yang digunakan sebagai eksplan serta faktor genetis pada tanaman duku yang digunakan (Prihatini et al. 2010). 


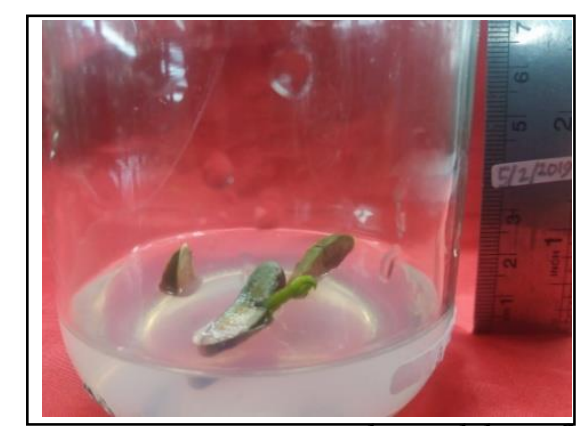

Gambar 1. Keragaan tunas yang muncul = perlakuan $3 \mathrm{mg} / \mathrm{L}$ BAP

\section{Jumlah Tunas}

Berdasarkan hasil analisis ANOVA pada Tabel 1 menunjukkan bahwa konsentrasi BAP tidak berpengaruh nyata terhadap jumlah tunas yang dihasilkan pada eksplan biji duku yang dibelah. Jumlah tunas yang dihasilkan pada penelitian ini berkisar antara $1-2$ tunas. Jumlah tunas paling banyak dihasilkan pada perlakuan $3 \mathrm{mg} / \mathrm{L}$ BAP yaitu 2 tunas, sedangkan jumlah tunas paling rendah dihasilkan pada kontrol yaitu 1 tunas. Pemberian konsentrasi BAP mampu meningkatkan jumlah tunas yang dihasilkan, namun jika diberikan konsentrasi tinggi akan menghambat jumlah tunas yang dihasilkan. Diduga konsentrasi $3 \mathrm{mg} / \mathrm{L}$ BAP sudah mampu meningkatkan jumlah tunas yang dihasilkan pada eksplan biji duku yang dibelah menjadi 3 bagian secara membujur. Hal ini mengindikasikan bahwa tanpa penambahan zpt ke dalam media kultur belum mampu untuk memicu pembelahan dan pembesaran sel sehingga jumlah tunas yang dihasilkan belum optimal. Menurut Wattimena (1992) bahwa salah satu penunjang pertumbuhan eksplan dalam teknik kultur in vitro adalah zat pengatur tumbuh.

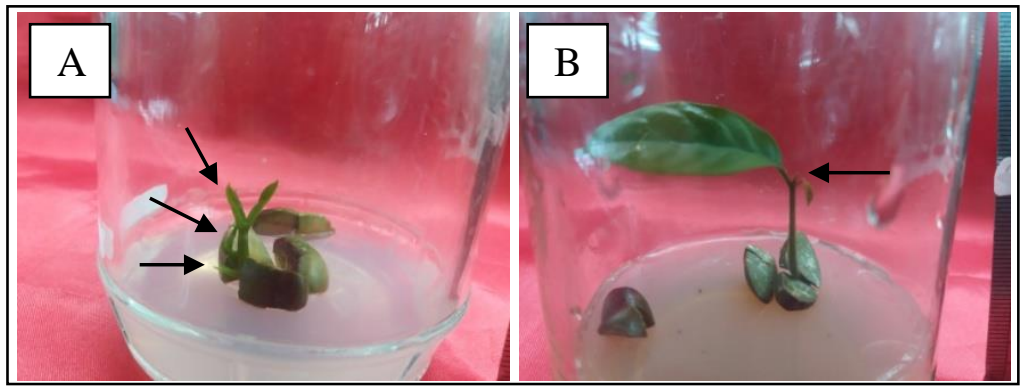

Gambar 2. Keragaan jumlah tunas. A = perlakuan $5 \mathrm{mg} / \mathrm{L}$ BAP; B = perlakuan kontrol; Keterangan : Tanda panah menunjukkan tunas

\section{Tinggi Tunas}

Hasil pengamatan tinggi tunas setelah dilakukan analisis ANOVA dan uji lanjut DMRT taraf $5 \%$ pada Tabel 1 menunjukkan bahwa pemberian BAP berpengaruh nyata terhadap parameter tinggi tunas. Perlakuan 1 $\mathrm{mg} / \mathrm{L}$ BAP berbeda nyata terhadap perlakuan lainnya. Namun, jika ditinjau dari angka yang dihasilkan terdapat perbedaan untuk semua perlakuan seperti terlihat pada Gambar 3. Pada perlakuan kontrol, 3, 5 dan $7 \mathrm{mg} / \mathrm{L}$ BAP terlihat dengan jelas perbedaan tinggi tunas yang didapatkan. Tunas tertinggi terdapat pada perlakuan $1 \mathrm{mg} / \mathrm{L}$ BAP yaitu $2,28 \mathrm{~cm}$ sedangkan tinggi tunas terendah terdapat pada perlakuan $7 \mathrm{mg} / \mathrm{L}$ BAP yaitu $0,38 \mathrm{~cm}$.
Berdasarkan hasil dapat dilihat bahwa pemberian BAP mampu mengindukasi sel-sel untuk berkembang dan bertambah ukuran sehingga meningkatkan tinggi tunas pada eksplan biji duku.

Terlihat pada hasil bahwa semakin tinggi konsentrasi BAP yang diberikan semakin menurunkan tinggi tunas yang dihasilkan dibanding dengan kontrol. Hal ini mengindikasikan bahwa eksplan biji duku tumbuh optimal pada konsentrasi BAP tidak lebih dari $1 \mathrm{mg} / \mathrm{L}$ BAP. Menurut Fathurrahman et al. (2012) pemberian ZPT eksogen yang berlebih akan menyebabkan terganggunya proses pembelahan sel yang akan mengarah pada terhambatnya tinggi tunas 
yang dihasilkan eksplan dalam kultur in vitro. Selain pengaruh konsentrasi BAP yang diberikan, tinggi tunas yang dihasilkan dari eksplan biji duku juga dipengaruhi oleh unsur hara pada media MS. Salah satu unsur hara yang memengaruhi adalah nitrogen. Kemampuan menyerap nitrogen dari media kultur akan memengaruhi pertumbuhan vegetatif pada eksplan. Unsur nitrogen yang diserap oleh eksplan mampu merangsang sintesis sitokinin yang berguna untuk pembentukan dan pertumbuhan tinggi tunas (Shintiavira et al. 2012).

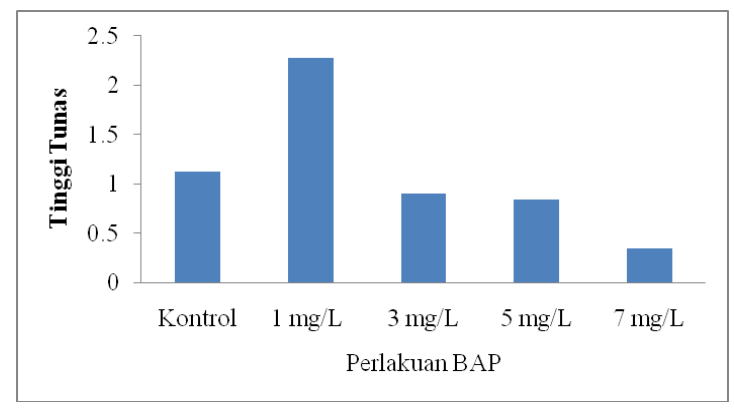

Gambar 3. Rata-rata tinggi tunas eksplan duku (Lansium domesticum Corr.)

\section{Jumlah Daun}

Hasil analisis ANOVA pada Tabel 1 menunjukkan bahwa pemberian konsentrasi BAP tidak berpengaruh nyata terhadap jumlah daun yang dihasilkan pada setiap tunas. Namun, jika dilihat dari angka yang dihasilkan terdapat pengaruh pemberian BAP. Jumlah daun yang dihasilkan berkisar antara $0,4-2,6$ daun. Jumlah daun tertinggi dihasilkan pada perlakuan $1 \mathrm{mg} / \mathrm{L}$ BAP yaitu 2,6 daun. Jumlah daun terendah terdapat pada perlakuan $5 \mathrm{mg} / \mathrm{L}$ BAP. Berdasarkan hal tersebut menunjukkan bahwa pemberian BAP mampu meningkatkan jumlah daun yang dihasilkan, meskipun belum maksimal. Pemberian $1 \mathrm{mg} / \mathrm{L}$ BAP sudah mampu meningkatkan jumlah daun pada ekplan biji duku. Singkatnya waktu pengamatan pada penelitian ini menyebabkan jumlah daun yang dihasilkan rendah. Karena daun yang dihitung yaitu daun yang sudah terbuka sempurna, sedangkan masing-masing tunas baru memiliki calon daun yang belum terbuka sempurna disebabkan lamanya waktu yang dibutuhkan untuk pembentukan tunas.

Menurut Shintiavira et al. (2012) jumlah daun dipengaruhi oleh komposisi unsur hara dalam media MS yang digunakan. Nitrogen merupakan unsur yang berpengaruh besar terhadap jumlah daun yang dihasilkan. Dimana pada konsentrasi yang tinggi mampu menghasilkan jumlah daun yang lebih banyak. Dilihat pada kontrol penelitian ini sudah menunjukkan hasil yang cukup dibandingkan dengan pemberian BAP. Hal ini menunjukkan bahwa komposisi unsur hara di dalam media mampu memicu pertumbuhan daun pada tunas eksplan.
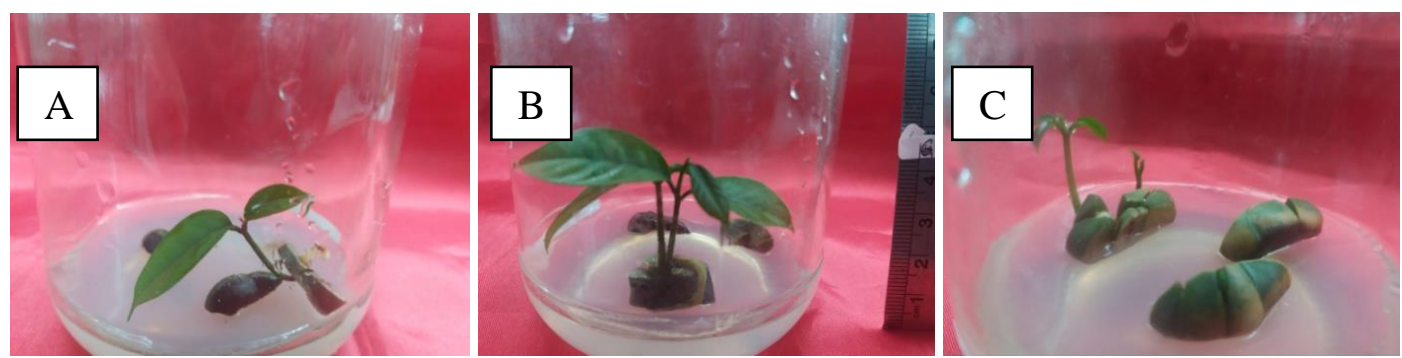

Gambar 4. Keragaan daun yang dihasilkan. A = perlakuan kontrol; B = perlakuan 1 BAP; $C=$ perlakuan 5 BAP 
Syafia Diang Rana dkk.

Tabel 2. Pengaruh pemberian BAP terhadap waktu muncul akar (MST) dan jumlah akar (Akar)

\begin{tabular}{ccc}
\hline \hline \multirow{2}{*}{ Perlakuan } & \multicolumn{2}{c}{ Parameter } \\
\cline { 2 - 3 } & Waktu Muncul Akar (MST) & Jumlah Akar (Akar) \\
\hline Kontrol & 1,40 & 0,40 \\
1 BAP & 1,00 & 0,40 \\
3 BAP & 0,80 & 0,20 \\
5 BAP & 0 & 0 \\
7 BAP & 0 & 0 \\
\hline \hline
\end{tabular}

Keterangan : Nilai signifikan lebih kecil dari 0,05 menunjukkan berpengaruh nyata pada analisis ANOVA.

\section{Waktu Muncul Akar}

Berdasarkan data hasil analisis ANOVA pada Tabel 2 menunjukkan bahwa pemberian konsentrasi BAP yang berbeda tidak berpengaruh nyata terhadap waktu muncul akar. Waktu muncul akar yang dihasilkan berkisar $0,80-1,00$ setelah 8 minggu penanaman. Waktu muncul akar tercepat terdapat pada perlakuan $3 \mathrm{BAP}$, waktu muncul akar paling lama pada perlakuan $1 \mathrm{mg} / \mathrm{L}$ BAP. Sedangkan pada perlakuan 5 dan $7 \mathrm{mg} / \mathrm{L}$ BAP tidak terdapat akar yang muncul (tidak membentuk akar). Tidak terbentukanya akar pada eksplan diduga dipengaruhi oleh ZPT yang digunakan. Pada penelitian ini menggunakan ZPT berupa BAP, BAP merupakan ZPT golongan sitokinin yang mampu merangsang sel-sel meristem pada eksplan untuk membelah dan berkembang menjadi tunas dan menghasilkan daun (Hidayat 1995). Sedangkan untuk pembentukan akar biasanya menggunakan ZPT dari golongan auksin. Rendahnya akar yang dihasilkan karena hormon endogen pendukung untuk pembentukan akar tidak mencukupi, sehingga membutuhkan penambahan hormon eksogen untuk menginduksi akar pada eksplan.

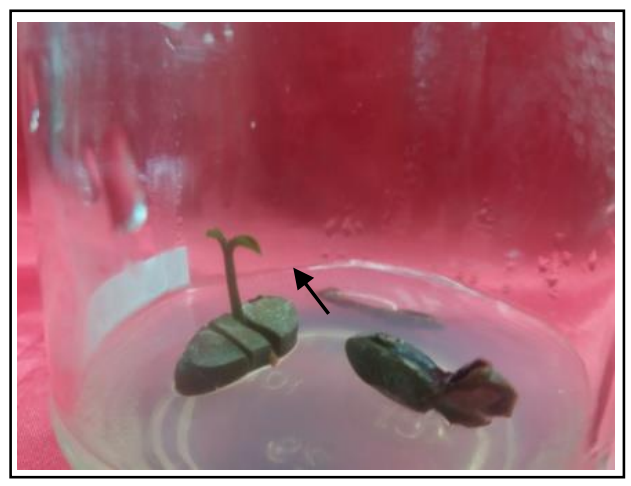

Gambar 5. Pertumbuhan akar = perlakuan $1 \mathrm{mg} / \mathrm{L}$ BAP (Tanda panah menunjukkan akar)

\section{Jumlah Akar}

Berdasarkan data hasil analisis ANOVA pada Tabel 2 menunjukkan bahwa pemberian konsentrasi BAP yang berbeda tidak berpengaruh nyata terhadap jumlah akar yang dihasilkan pada eksplan biji duku. Jumlah akar terbanyak dihasilkan pada perlakuan kontrol dan $1 \mathrm{mg} / \mathrm{L}$ BAP yaitu 0,40 akar, perlakuan 3 mg/L BAP menghasilkan 0,20 akar dan pada perlakuan 5 dan $7 \mathrm{mg} / \mathrm{L}$ BAP tidak menghasilkan akar sama sekali. Berdasarkan hasil, dapat dilihat bahwa eksplan biji duku yang digunakan mengandung auksin endogen yang tinggi sehingga mampu menumbuhkan akar. Terlihat pada perlakuan kontrol yaitu tanpa penambahan ZPT menghasilkan jumlah akar yang tinggi yaitu 0,40 akar. Menurut Lestari (2011) pemberian ZPT berupa auksin atau sitokinin dalam media kultur in vitro mampu meningkatkan induksi akar. Hasil jumlah akar pada penelitian ini dapat dikatakan masih rendah, karena pada media kultur yang digunakan tidak ditambahkan ZPT auksin untuk menginduksi akar pada eksplan, yang digunakan hanyalah BAP yang berfungsi untuk menginduksi tunas. Menurut Simanjuntak et al. (2017) interaksi antagonis antara auksin dan sitokinin adalah salah satu cara tanaman untuk mengatur pertumbuhan dan perkembangan akar. 


\section{Simpulan dan Saran}

\section{Simpulan}

Respon poliembrioni biji duku (Lansium domesticum Corr.) yang dibelah pada media MS dengan pemberian $\operatorname{BAP}(0,1,3,5$ dan 7 BAP) menunjukkan bahwa rerata waktu muncul tunas tercepat terdapat pada konsentrasi 1 BAP yaitu 2,20 MST dengan rerata jumlah tunas tertinggi pada konsentrasi 3 BAP yaitu 2 tunas. Rerata waktu muncul akar tercepat pada kontrol dan 1 BAP yaitu 1,40 MST dengan rerata jumlah akar tertinggi yaitu 0,40 akar.

\section{Saran}

Penelitian lanjutan perlu dilakukan dengan menggunakan zat pengatur tumbuh lain untuk mengindukasi perakaran pada tunas duku.

\section{Ucapan Terima Kasih}

Penelitian ini didanai oleh Kemenristek Dikti melalui Program Kreativitas Mahasiswa (PKM) tahun anggaran 2019.

\section{Daftar Pustaka}

Fathurrahman, Rormawati T., Nasution A.S. \& Gunawan S. 2012. Multiplikasi Tunas Pucuk Tomat (Lycopersicum esculentum Mill) dengan Menggunakan Benzyl Amino Purine (BAP) dan Naphtalene Acetic Acid (NAA) Secara In Vitro. Jurnal Agroteknologi 1(1): 1 - 12.

Hariono, E., M. N. Isda \& S. Fatonah. 2018. Pembentukan Nodul Dari Biji Manggis (Garcinia mangostana L.) Asal Bengkalis pada Media WPM dengan Penambahan BAP dan Madu. Journal of Biology 11(1): 16 - 24.

Hidayat, E. B. 2011. Anatomi Tumbuhan Berbiji. Bandung : ITB.
Lestari, E. G. 2011. Peranan Zat Pengatur Tumbuh dalam Perbanyakan Tanaman Melalui Kultur Jaringan. Jurnal Eugenia 6(1).

Prihatini, R., S. Yahya dan A. Purwito. 2010. Kultur Poliembrioni Biji Duku (Lansium domesticum Corr.) pada Media MS dan WPM dengan Penambahan Air Kelapa. Jurnal Saintek 11(1): 7 - 11.

Rahmawati, R. Y., M. N. Isda \& S. Fatonah. 2014. Induksi Tunas dari Eksplan Biji Manggis (Garcinia mangostana L.) Asal Bengkalis Secara In Vitro dengan Perlakuan BAP (Benzylaminopurine) pada Media MS. Jom Fmipa 1(2): 263 - 268.

Shintiavira, H., Soedarjo M., Suryawati \& Winarto B.2012. Studi Pengaruh Substitusi Hara Makro dan Mikro Media MS dengan Pupuk Majemuk dalam Kultur In Vitro Krisan. J.Hort 21(4):334 - 341.

Simanjuntak, N. A., L. A. M. Siregar \& L. A. P. Putri. 2017. Pengaruh Zat Pengatur Tumbuh Terhadap Induksi Akar (Rhizogenesis) pada Tanaman Bangun-Bangun (Plectranthus amboinicus (Lour.) Spreng) Secara In Vitro. Jurnal Agroteknologi FP USU 5(3):644 649.

Supriatn, A. \& Suparwoto. 2010. Teknologi Pembibitan Duku dan Prospek Pengembangannya.Jurnal Litbang pertanian 29(1): $19-24$.

Susilawati, Munandar \& J. D. Merida. 2016. Kajian Ragam Aksesi Duku (Lansium domesticum Corr.) di Kabupaten Musi Banyuasin Berdasarkan Karakter Morfologi, Anatomi dan Fisiologi. Jurnal Lahan Suboptimal 5(1): $105-118$.

Syah, I. S. K. 2016. Penentuan Tingkat Jaminan Sterilisasi pada Autoklaf dengan Indikator Biologi Spore Strip. Farmaka 14(1): 59 - 69.

Triatminingsih, R., Karsinah, H. Subakti \& I Fitrianingsih. 2003. Kultur In Vitro Biji Duku. J.Hort 12(2): $77-81$.

Wattimena, G.A. 1992. Diktat Zat Pengatur Tumbuh Tanaman. Bogor : Laboratorium Kultur Jringan Tanaman PAU Bioteknologi IPB Direktorat Jendral Pendidikan Tertinggi Depertemen Pendidikan dan Kebudayaan. 